\title{
The Construction of Female Images in Chinese TV Dramas From 2009 to 2018
}

\begin{abstract}
Cheng $\mathrm{Li}^{1, *}$
${ }^{1}$ Beijing Normal University, Zhuhai, Zhuhai, Guangdong, China

"Corresponding author. Email: licheng@bnuz.edu.cn

ABSTRACT

TV drama creation takes real life as the source of creation, restoring real life scenes, and not only presents the audience's life experience in various fields through different themes, but also affects the audience's perception of life. The images of female characters in TV dramas are gradually diversified, but there are still certain stereotypes about women. Based on the list of "Annual Selected Works of Chinese TV Dramas" published by the State Administration of Press, Publication, Radio, Film and Television of China from 2009 to 2018, 123 TV dramas were selected from 246 TV dramas, and 272 female characters appeared as the research objects. Through the four aspects of body appearance, inner character, ethical role, and professional identity, the content analysis of the female role image in TV dramas is carried out to obtain the characteristics of the female role image in Chinese TV dramas and the hidden problems in the construction of female images. Finally, corresponding suggestions are made.
\end{abstract}

Keywords: TV drama, female image, frame theory, content analysis

\section{INTRODUCTION}

TV drama is an art form that integrates many artistic elements. It brings together stories, phenomena, and popular elements in real life, which are interpreted by actors and presented to the audience on the screen. It carries the current popular culture in society and meets the entertainment needs of the people in daily life. The characters and plots in TV dramas often become topics of heated discussion among the public, and at the same time influence people's lifestyles and values. The images of the characters in the TV dramas that are deeply rooted in the hearts of the people are not only a reflection of real life, but also an artistic expression. In the past, most TV dramas focused on men. With the awakening of Chinese feminist consciousness, TV dramas with powerful female themes on the screen have been enriched. TV dramas of other themes also have many distinctive female characters, and their influence in TV dramas is also increasing. According to the "2018 Weibo Drama Series White Paper", in 2018, there were 130 million users interested in drama series, indicating that the audience of TV dramas is very wide.

Although TV dramas are fictitious TV texts, they are derived from TV drama creators' perceptions and ideas of life experiences and phenomena. The audiences compare the plots and characters shown in TV dramas to real life. It is precisely because of the attributes of TV dramas that people will be influenced by the plots or characters created by TV dramas and the social culture or consciousness contained in them, especially female culture. The images of TV dramas are continuously strengthened with simple and repetitive symbols and codes, and the audiences' satisfaction of entertainment needs is also constructing their own understanding of society. The image of female characters portrayed by TV dramas shows the public's understanding and attitude towards women.

Based on the framework theory and the use of content analysis methods to study the female character images portrayed in the "Annual Anthology of Chinese TV Dramas" by the State Administration of Press, Publication, Radio, Film and Television from 2009 to 2018 as a sample, this article reveals how the Chinese Year TV dramas construct female images and the problems.

\section{LITERATURE REVIEW}

\section{A. Frame theory}

The concept of frame first came from "A Theory about Drama or Fantasy" by the British psychologist Bessant, and was later introduced into the field of sociology by the American socioculturalist Goffman. Goffman believes that the formation of the frame comes from people's past experience, and different cultural and social experiences will create different cognitive frames. Therefore, different people have different interpretations of things. 
The frame is used by Gamsang in the field of communication. Professor Huang Dan pointed out in his book "Communication Image: The Construction and Deconstruction of Journalism Professionalism": "(It is) the principle of choice, emphasizing and presenting constituted by default theories, to tell people what exists, what happened, and what is crucial". In his "Summarization of Framework Theory from the Perspective of Communication Studies", Qiao Xinyu summarized the commonalities from many scholars' understanding of the frame: "The frame is an existence that through choice and combination, it can influence how people interpret the external world". Frame analysis has become an important research method of communication and has been widely used by scholars in China and foreign countries, such as media production, media content, and media effects. Through the frame, the spreader defines his own understanding of the phenomena of social life in a certain viewpoint, which affects the audience's objective and rational understanding of real life.

\section{B. Research status}

In CNKI (China National Knowledge Internet), using "television drama", "female" and "frame" as keywords, the researchers searched out 75 documents and there are 71 dissertations for doctoral and master's degree. Wang Liting's "Adaptation, Breakthrough, Remodeling: Construction and Interpretation of Female Images in Contemporary TV Series: Based on an Investigation of the Golden Eagle Award-winning Female Characters" analyzes the four levels of appearance, personality, living space and occupation of women in TV dramas from the perspective of patriarchy, feminism and post-modern culture. There are 11 articles on the theme of "female images", among which $\mathrm{Hu}$ Tianxia's "Visual Illusions in the Gaze Analysis of Female Images in TV Plays" (2010) uses "gaze" theory and content analysis to analyze the images of women in TV dramas. Liu Shujun's "Research on Female Images in TV Series on Family Ethics" (2014) analyzes the female images in family ethics TV dramas from a critical point of view, expounding the cultural hegemony of gender hidden behind the female images in TV dramas. Wang Ying's "The Evolution of Female Images in TV Dramas from the Perspective of Consumer Culture" (2012) and "The Breakthrough of the "Other": A Study on the Transmutation of Wife Images in Chinese Family Ethics Dramas" are analyzed from the perspective of the changes in female images in TV dramas (2016). The former researched the 1990-2010 TV dramas in the social context of consumer culture in terms of the interaction between women and consumption, the construction of the female image of the TV dramas and the main body of creation; the latter analyzed the changes in the image of "wife" in the TV dramas and whether the wife's right to speak is obtained or not.
Laura Stempel Mumford's "Afternoon Love and Ideology Soap Operas, Women, and TV Dramas" (Lin He, trans, 2000) starts from a feminist standpoint, takes the soap operas that American women love to watch with fiction and exposing privacy as the research object, and believes that this kind of narrative strategy can hide the patriarchal ideology and spread and strengthen it. "Malay women as discerning viewers: Negotiating images of transnational modernity in Asian soap operas" (2011) talks about the influence of consumerism in Asian soap operas on Malaysian women who love to watch Asian soap operas by investigating rural women in Malaysia.

\section{RESEARCH DESIGN}

Since 2009, the State Administration of Radio and Television (formerly the State Administration of Press, Publication, Radio, Film and Television) has selected the previous year's TV series at the beginning of each year to list the "Annual Selections of Chinese TV Dramas" and publish them in this form.

Searched the "Chinese TV Series Annual Anthology" on Dongfang.com - Dongfang News website, people can obtain a total of $246 \mathrm{TV}$ dramas selected from 2009 to 2018. Numbering 246 TV dramas, using systematic sampling method to select 123 TV series, except for a few of which do not have the names of female actors on the starring list or the female characters that are not prominent in the plot, such as "Peiping War and Peace" and "Tea House", the final effective TV dramas samples totaled 117. There are a total of 272 female characters, and these female characters are finally sorted and numbered as research samples.

In this paper, 272 samples of female roles are classified and coded according to the four dimensions of physical appearance, inner personality, ethical role and professional identity, referring to research on the frame of female image of Ma Lin's doctoral thesis "The Female in Media Framing of Teleplays Express: Images Composition and Status Identity" (2008), Sun Mengyuan's master's thesis "Study on Female Images in Domestic Urban Emotional Plays since the New Century-Take the 'Golden Eagle Award' as an Example" (2018), Guo Meiling's master's thesis "Research on the Wife Image of Family Ethics Drama of 'Feitian Award"' (2018), and the journal paper by Qi Yalin and Zhong Chengxiang "Research on the Frame of the Image of Rural Women in Chinese TV Dramas - Taking the Rural Theme Dramas That Won the 'Feitian Award' from 1983 to 2015 as the Research Object" (2016).

\section{A. Body appearance}

The code uses age and appearance as indicators, and age is one of the factors to examine women. It is mainly 
divided into youth, middle age, and old age. According to the standards of the National Bureau of Statistics of China, the youth group is defined as 15-34 years old. In China, citizens over 60 years old are defined as elderly people, and middle-aged people are between young and old, and between 35-59 years old. Some characters span the three stages of youth, middle age, and old age, and when determining their age group, the researchers choose the age group with a relatively high proportion in the TV dramas. The appearance is divided into three indicators: beautiful, general, and not beautiful. It is mainly based on the description of the appearance characteristics of the female characters in the TV dramas. Because the female characters in some TV dramas focus not on their appearance characteristics, but pay attention to their personality characteristics or professionalism, so they will be put in the general ranks.

\section{B. Inner character}

The codes are divided into some categories: 1) simple, kind, selfless, and devoted; 2) gentle, considerate, diligent and thrifty; 3) positive, aggressive, firm and persistent; 4) fashion, publicity, decisive and capable; 5) relying on enjoyment and pursuing material; 6) bold, daring to love and hate; 7) traditional, introverted, weak, and dependency. The core character of the female image examined, demonstrates the construction of the female character in the image frame of the TV dramas.

\section{Ethical role}

The codes are mainly wives, mothers, daughters, lovers (women in a state of love), and third parties. Because some characters in TV dramas not only have one ethical identity, the changes in ethical roles promote the development of the plot, but also have a more important connection with the fate of the characters in the drama, so there are two or more repetitive calculations of the main ethical roles.

\section{Occupational identity}

The codes are teachers, company white-collar workers, managers, designers, media workers, service workers, medical staff, freelancers, technicians, unemployed, rural women or housewives, rural cadres, urban migrant workers, rich rural people, educated youth or volunteers from the provinces and cities, government officials, etc.

\section{RESEARCH ANALYSIS}

\section{A. Body appearance}

In the era of visual culture and consumerism, the female body is an important object of examination. As an important output of visual cultural consumption, TV dramas also contain female characters' body images. The female images of the TV dramas are shaped by the creator based on his own imagination, as well as his own experience and social environment, giving the creator a personal understanding and expression of the female images. The perfect image presented by the female characters in the TV dramas is not only one of the factors that attract the audiences, but also allows women in reality to imitate and learn, and to satisfy men's visual desires for women.

Female characters in China TV dramas are mostly youth, up to $76.48 \%$, while middle-aged women and old women account for a relatively small proportion, $19.48 \%$ and $4.04 \%$ respectively. It can be seen that most of the TV dramas creators choose young women as their main targets when shaping female characters, such as Song Nuan and Zhou Gege in "Best Get Going", Luo Yiren in "Game of Hunting" and other young and beautiful women. Song Nuan and Zhou Gege are students who are preparing to graduate from university, full of youth; Luo Yiren in "Game of Hunting" was 25 years old at the beginning and 29 years old at the end, and there is not much difference in age. And some TV dramas show the life of women, such as the Xiancao in "White Deer Plain", which was more than ten years old at first and was only 38 years old when she died of illness. "The Story of Zheng Yang Gate" portrays the legend of the two women $\mathrm{Xu}$ Huizhen and Chen Huiru. From Deng Xiquan, Li Chi, and $\mathrm{Xu}$ Hongfang's "Statistical Report on China's Youth Population and Development(2018)", it can be seen that the total number and proportion of China's youth population have declined, while the decline in female youth is even greater. Chinese young women account for $31.02 \%$ of the national female population. It can be seen that the current female population in China is that middle-aged and elderly women account for the majority, and the proportion of young women in TV dramas is higher than that in the real society. The age portrayal of female images in TV dramas is too concentrated on young women, neglecting to explore and create the lives of women of other age groups.

In many TV dramas, the proportion of beautiful female characters is the highest, reaching $59.55 \%$, while the less beautiful female characters are very few, only $1.47 \%$. Therefore, TV dramas creators focus on creating beautiful female characters, and ugly-looking female characters are rarely accepted by the public. The public always has a certain pursuit of beauty, and TV dramas are a form of popular art. Beautiful women are easy to attract the attention of the audiences, especially the male audiences. In real life, beautiful women are always more attractive and more advantageous. The female images in TV dramas will choose good-looking women as the main characters in TV dramas in order to cater to public tastes and satisfy male visual desires. 


\section{B. Inner character}

In addition to the appearance characteristics of a person, his or her character performance is also an important symbol of his or her attraction. The characters portrayed in TV dramas all have distinctive personality characteristics, which are mainly manifested in their attitudes and behaviors towards people and things. The development of the plot and the direction of the characters are also promoted by the character of the characters. Affected by the creator, different social environments and life experiences will have different character personalities.

Among the female characters in the TV dramas, $32.35 \%$ are aggressive, firm and persistent female characters, followed by bold and daring to love and hate, accounting for $16.18 \%$, and then the traditional, introverted, weak and dependent, accounting for $14.34 \%$. Due to the different environment of the times, the focus of characterization of female characters is also different. The number of female characters who are active and persistent, daring to love and hate, and decisive and capable is gradually increasing due to the improvement of women's social status. For example, Tang Jing in "The First Half of My Life" presents the image of fashionable and capable professional women in the play, and Xia Bing presents the fashionable and bold image in "Hot Mom". Nowadays, audiences are fonder of female characters who are independent and daring to love and hate. Although the image of kind, gentle and considerate female characters is very good, the independent and public women show the modern female consciousness and embody the style of women in the new era. It can be seen that in the past ten years, the personalities of female characters in Chinese TV dramas have also been enriched with changes in the social environment, and the characterization of the characters has become more stereoscopic.

\section{Ethical role}

In China's thousands of years of history and culture, the feudal patriarchal society has strict requirements for the construction of gender relations, as do women's ethics. The status of women in ancient society was not as good as that of men and usually depended on the social status of men. Furthermore, the life scenes of ancient women were mostly located in the family, and their entire lives revolved around husbands and children. In the new era, the different social environment has given many women more choices in ethical roles.

The ethical roles of women in TV dramas are inseparable from the three universal roles of mother, wife, and daughter. Mothers account for $34.56 \%$, wives $46.70 \%$, and daughters $23.90 \%$. It can be seen that the shaping of female ethical roles in TV dramas will focus on the two most basic images of mother and wife. For example, Cheng Kaiyan in "Like a Flowing River" and Tong Jiaqian in "Naked Marriage Age" belong to the three family roles. In reality, the ethical roles played by women in the family are usually mothers, wives and daughters. The ethical role of women with the development of the times and the awakening of female consciousness is not only here, women's freedom is liberated, and their love, marriage, and childbirth can all be freely chosen. There are also the emergence of the ethical image of the "third party", such as Ling Ling in "First Half of My Life" and Gao Xiaoqin in "In the Name of People". According to data from the National Data Website, the number of registered marriages has been on the decline in recent years, while the number of divorces has increased. People are more cautious about marriage choices. The image of wives in TV dramas still accounts for a relatively high proportion. TV dramas on family ethics in China are mostly based on mother-in-law and daughter-in-law, causing conflicts between husband and wife and never digging into the topic of marriage.

\section{Occupational identity}

With the development of the times and the progress of society, more and more women get rid of the shackles of being attached to men and separated from the family, and begin to move towards the society to realize their self-worth. When TV drama creators create female roles, their professional identities are gradually diversified. Women can enter various fields of society and take up roles regardless of their family environment.

The analysis of these women's occupations shows that women's occupational identities are more abundant in modern society. Government officials accounted for $12.87 \%$, followed by rural women or housewives, accounting for $10.28 \%$, company white-collar workers accounting for $7.35 \%$, and service industry personnel accounting for $6.25 \%$. Women of government agencies accounted for $12.87 \%$, managers accounted for $5.88 \%$, and rural women accounted for $10.28 \%$, while rural cadres only accounted for $0.37 \%$. It can be seen that TV dramas have relatively few women participating in decision-making. However, the situation of rural women's political participation in the TV dramas is still similar to reality.

\section{CONCLUSION}

In summary, the image construction of female roles in Chinese TV dramas is dominated by young and beautiful young women, with diversified personality characteristics, mostly family ethical roles, and the career choices of female roles are more diverse.

First of all, the age groups of women presented in TV dramas are mostly concentrated in the youth stage, and their looks are mostly beautiful. Therefore, the 
main female roles in most TV dramas are seldom middle-aged and elderly women. The female characters created by TV drama creators are single and lack attention to middle-aged and elderly women. Secondly, the female characters in TV dramas in the past ten years are rich in personalities, and the female images portrayed are more three-dimensional. They are not limited to shaping gentle, virtuous, weak and incompetent women. As women enter society and the workplace, the image of fashionable and capable women who dare to love and hate has increased in recent years, which can attract the attention of the audiences and provide more ideas for the fate of female characters. Third, the ethical roles of women in TV dramas are mostly mothers, wives and daughters. Marriage, family, and childbirth are still women's final destinations. Although it is a manifestation of the status quo of society, it ignores the more possibilities of the living conditions of unmarried women. Finally, the career of female roles in TV dramas is not limited to the family, and the types of occupations cover multiple fields. Women enter the public domain of society and pursue the realization of self-worth.

At the same time, there are also certain problems with the image of female characters in Chinese TV dramas.

First, the body images of female characters in TV dramas are too centralized. The body images of women in TV dramas are focused on youth and beauty. Most young women are shaped for beautiful looks, while middle-aged women and old women do not highlight their appearance due to age. For example, the mother of Yuan Bao in "Hot Mom" is portrayed as a traditionally introverted mother who depends on her son. Moreover, the roles of middle-aged and elderly women are mostly mothers and above, but they lack their attitudes towards life, work, marriage, etc. Their main scenes are in the family, and these kind of single scenes limit their image shaping. In addition, TV drama creators tend to be younger in the construction of female roles, which leads to a lack of diversity in female images and causes an imbalance in the female actor market.

Second, it is the repetition of female characters in TV dramas. Female characters are rich in character shaping, but they are mostly positive in character performance, showing repetitiveness. The characterization of characters is divorced from reality. "Truth, goodness and beauty" are the beautiful qualities that people pursue, but people are complicated, and a person's personality is also complicated. The character of a character should be shaped more threedimensionally, and the audiences will have a sense of substitution. The character portrayal of female characters is therefore more distinctive. Not every character has the same characteristics. They are the incarnation of "truth, goodness and beauty". Every character will have her lack of personality, and it will be more discussion and thinking for characters with complex personality.

Third, the proportion of female roles in TV dramas is uneven. Women's occupational types are becoming more abundant, modern women's level of education is getting higher and higher, as are professional and economic abilities, and their roles in the social field are becoming more and more important. Although women's occupations in TV dramas are relatively diverse, the types of occupations of female roles are not balanced. For example, the women in the occupations such as designers, professional technicians, rural cadres, and rural wealthy people are few. In contrast, housewives, teachers, medical staff, etc. are relatively more. The creators did not explore the role of women in many fields of society and their performance in the workplace and reflect their value.

The creators of TV dramas need to explore more possibilities of female characters. It is necessary to shape the roles of women of different age groups, and pay attention to the status quo and life of middle-aged women in society or in the workplace. Compared with men, women face greater pressure and discrimination in society or in the workplace. Improving the screen image of middle-aged and older women will help society to give more care and respect to middle-aged and older women. TV dramas should also reflect women's social values and career abilities. Although the career types of female characters in TV dramas are diverse, the performance of women in the workplace is easily overlooked or concealed by the career performance of male roles. In addition, the careers of female roles in TV dramas are mostly traditional female occupations. Some TV dramas show the success of female roles in the workplace as relying on the power of male roles, which dilutes women's career ability and social value. Female roles' professional qualities and social abilities should be highlighted in more fields, showing the style of independent women in the new era and modern female consciousness.

\section{References}

[1] Sun Mengyuan, Study on Female Images in Domestic Urban Emotional Plays sincn the New Century-Take the "Golden Eagle Award" as an Example [D]. Nanchang University, 2018 (in Chinese)

[2] Guo Meiling, Research on the Wife Image of Family Ethics Drama of "Feitian Award" [D]. Jinan University, 2018. (in Chinese)

[3] Hou Lijuan, The Presentation and Thinking of the Female Images in the Hot TV Dramas in Recent Years [D]. Nanchang University, 2018. (in Chinese)

[4] Wang Dongyu, Research on the Evolution of Female Images in the Workplace of Chinese Urban Drama [D]. Kunming University of Science and Technology, 2018. (in Chinese) 
[5] Qi Yalin, Zhong Chengxiang, Research on the Frame of the Image of Rural Women in Chinese TV Dramas - Taking the Rural Theme Dramas That Won the "Feitian Award" from 1983 to 2015 as the Research Object [J]. Modern Communication (Journal of Communication University of China), 2016, 38(09): 76-81+99. (in Chinese)

[6] Ma Lin, The Female in Media Framing of Teleplays Express: Images Composition and Status Identity [D]. East China Normal University, 2008. (in Chinese)

[7] Li Lan, A Study of Female Images in Chinese Urban TV Series [D]. Shandong Normal University, 2018. (in Chinese)

[8] Tang Chengling, Female Image Creation in Domestic Urban Emotional Dramas in the Context of Internet-TV Station Linkage Broadcasting [D]. Shanghai Normal University,

[9] 2018. (in Chinese)

[10] Wang Liting, Adaptation, Breakthrough, Remodeling: Construction and Interpretation of Female Images in Contemporary TV Series [D]. Anhui University, 2018. (in Chinese)

[11] Chen Dengqi, Research on Female Stereotypes in Chinese Urban Emotional Movies and TV Works [J]. TV Guide China, 2017(18): 26. (in Chinese)

[12] Zhang Ting, Research on Female Images in Domestic Youth Idol Dramas in the New Century [D]. Heilongjiang University, 2015. (in Chinese)

[13] Jiang Leiyi, The Breakthrough of the "Other": A Study on the Transmutation of Wife Images in Chinese Family Ethics Dramas [D]. Anhui University, 2016. (in Chinese)

[14] Liu Shujun, Research on Female Images in TV Series on Family Ethics [D]. Heilongjiang University, 2014. (in Chinese)

[15] Hu Tianxia, Visual Illusions in the Gaze [D]. Anhui University, 2010. (in Chinese)

[16] Liu Chang, Feminist Changes in Film and Television Dramas - Analysis of the Content of Popular Film and Television Dramas [J]. Radio \& TV Journal, 2018(09): 48-49. (in Chinese)

[17] Kang Luchen, Chen Hongmei, The Creation and Innovation of Female Images in Contemporary Urban Theme Dramas: Taking "The First Half of My Life" as an Example [J]. Anhui Literature, 2018(07): 80-81. (in Chinese)

[18] Qi Shixin, An Analysis of the Female Image in the TV Play Nirvana in Fire [J]. Journal of Cangzhou Teachers' College,

[19] 2018, 34(02): 61-63+72. (in Chinese)

[20] Deng Xiquan, Li Jie, Xu Hongfang, Statistical Report on China's Youth Population and Development(2018) [J]. Journal of Guangdong Youth Vocatjonal College, 2018, 32(04): 5-13. (in Chinese)

[21] Zhang Haoming, Analysis of Feminism in "Nothing Gold Can Stay" [J]. Research on Transmission Competence, 2018, 2(09): 43-44. (in Chinese)

[22] $\mathrm{Yu}$ Bo, The Cross-cultural Deconstruction of the Image of Young Women in the Media — Taking "Broken Sisters" and "The Story of Hot Mom" as Examples [J]. Radio \& TV Journal, 2017(11): 40. (in Chinese)

[23] Li Huan, On the Cultural Cognition of the Female Images in the TV Play "Ode To Joy" [J]. Popular Literature, 2016(21): 205. (in Chinese)

[24] Sun Yiting, The Dissemination Bias of Female Images in Hit Dramas - Research Based on Content Analysis [J]. Aesthetics, 2015(05): 119-123. (in Chinese)

[25] Motsaathebe, Gilbert. Gendered roles, images and behavioural patterns in the soap opera Generations[J]. Journal of African Media Studies, 1(3):429-448.

[26] BarrieGunter, MalloryWober. Television viewing and perceptions of women's roles on television and in real life[J]. Current Psychological Reviews, 1982, 2(4):277-288.
[27] Qiao Xinyu, A Summary of Frame Theory from the Perspective of Communication Studies [J]. Journal of Shangqiu Normal University, 2011, 27(10): 126-128. (in Chinese) 